\title{
Deletion of the Serotonin Receptor Type 3A in Mice Leads to Sudden Cardiac Death During Pregnancy
}

\author{
Hyewon Park, BSc; Chang-Myung Oh, MD; Junbeom Park, MD, PhD; Hyelim Park, BSc; \\ Shanyu Cui, PhD; Hyung Suk Kim, MD; Jun Namkung, MD, PhD; Sang-kyu Park, MD, PhD; \\ Hui-Nam Pak, MD, PhD; Moon-Hyoung Lee, MD, PhD; Hail Kim, MD, PhD; Boyoung Joung, MD, PhD
}

\begin{abstract}
Background: The serotonin receptor type $3(\mathrm{Htr} 3)$ blocker is associated with QT prolongation and torsades de pointes. However, little is known about effects of $\mathrm{Htr} 3$ on the heart arrhythmia.
\end{abstract}

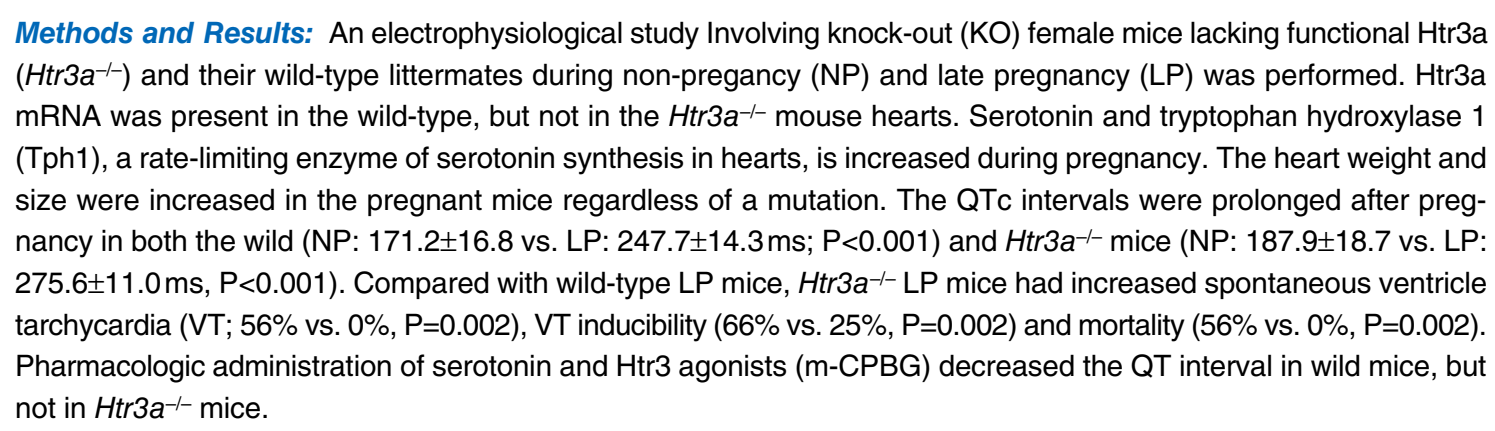

Conclusions: Htr3a is present in mouse hearts. Serotonin and Tph1 were increased during pregnancy. The deletion of Htr3a was related to fatal arrhythmias and sudden cardiac death during pregnancy, and its activation reversed the QT prolongation. (Circ J 2015; 79: 1807-1815)

Key Words: Fatal arrhythmia; Pregnancy; QT prolongation; Serotonin receptor type 3

$\mathbf{S}$ erotonin, 5-hydroxytryptamine (5-HT), was first isolated as a vasoconstrictor from the blood, and was later identified in the central nervous system (CNS). It is found in 3 main areas of the body: the intestinal wall, platelets, and the CNS. The functions of 5-HT in the CNS as a neurotransmitter are numerous and appear to involve control of appetite, sleep, memory, behavior (including sexual and hallucinogenic behavior), and endocrine regulation. ${ }^{1}$ Tryptophan hydroxylase 1 (Tph1) is a rate-limiting enzyme of 5-HT synthesis in peripheral tissues. Peripherally, 5-HT, which is stored in platelets, appears to play a major role in homeostasis, blood pressure regulation, cardiovascular functions, ${ }^{1}$ motility of the gastrointestinal tract, ${ }^{2}$ and carcinoid tumor pathology. The role of 5-HT in the heart has been demonstrated by cardiac dysfunction in
Tph1 knock-out (KO) mice and/or 5-HT2b receptor KO mice..$^{3,4}$ These biological actions of 5-HT are mediated by numerous cognate receptors. It now appears that there are at least 15 receptor subtypes that belong to 4 populations: 5-HT1/5, 5-HT2, 5-HT3, and 5-HT4/6/7 subtypes. ${ }^{5}$

Unlike the other serotonin receptor genes in the mouse genome, which encode G-protein-coupled serotonin receptors, Htr3a encodes subunits of the ligand-gated cation channels, and is essential to form a functional Htr3 channel..$^{6-8}$ However, the precise role of Htr3 as an ion channel expressed in the heart has not been fully evaluated. Htr3 antagonists, including granisetron (Kytril) and ondansetron (Zofran), are widely used for the treatment of postoperative and chemotherapy-induced nausea/vomiting. They have been reported to widen the QRS

Received October 5, 2014; revised manuscript received March 31, 2015; accepted April 5, 2015; released online May 15, 2015 Time for primary review: 24 days

Division of Cardiology, Yonsei University College of Medicine, Seoul (Hyewon P., J.P., Hyelim P., S.C., H.-N.P., M.-H.L., B.J.); Graduate School of Medical Science and Engineering, Korea Advanced Institute of Science and Technology, Daejeon (C.-M.O., H.S.K., J.N., S.-k.P., H.K.); Brain Korea 21 PLUS Project for Medical Science, Yonsei University, Seoul (Hyelim P.); and Division of Cardiology, School of Medicine, Ewha Womans University, Seoul (J.P.), Korea

First three authors contributed equally to this study (Hyewon P., C.-M.O., J.P.).

Mailing address: Boyoung Joung, MD, PhD, Cardiology Division, Department of Internal Medicine, Yonsei University College of Medicine, 250 Seungsanno, Seodaemun-gu, Seoul 120-752, Republic of Korea. E-mail: cby6908@yuhs.ac and Hail Kim, MD, PhD, Graduate School of Medical Science \& Engineering, KAIST, 291 Daehak-ro, Youseong-gu, Daejeon 305-701, Republic of Korea. E-mail: hailkim@kaist.edu

ISSN-1346-9843 doi:10.1253/circj.CJ-14-1074

All rights are reserved to the Japanese Circulation Society. For permissions, please e-mail: cj@j-circ.or.jp 
complex, and prolong the JT, QT, and PR intervals. Htr3 antagonists at high concentrations induce cardiac dysrhythmias with the risk of QT prolongation. ${ }^{9-12}$

We hypothesized that serotonin may have a role in preventing QT prolongation through Htr3a. To prove this hypothesis, we identified the presence of Htr3a, serotonin, and Tph1 in the heart. Pregnancy is a well-known condition during which the heart undergoes various hemodynamic and structural changes, with an increase in cardiovascular events. ${ }^{13,14}$ It was reported that the serum serotonin level increased 2-fold during pregnancy. ${ }^{15}$ Therefore, we evaluated the change in serotonin and Tph1 in the heart during pregnancy. We also analyzed the QT interval changes and arrhythmias in wild type and $\mathrm{Htr}_{3} \mathrm{a}^{-1}$ mice during pregnancy. Finally, we demonstrated that the pharmacological administration of a serotonin and Htr3 agonist (m-CPBG) could reverse the QT prolongation.

\section{Methods}

This investigation conformed to the Guide for the Care and Use of Laboratory Animals published by the US National Institutes of Health (Animals were cared for in strict accordance with the National Institutes of Health (NIH) Guide for the Care and Use of Laboratory Animals. All experimental protocols were reviewed and approved by the institutional animal care and Use committee of Yonsei University College of Medicine and Cardiovascular Research Institute). This study protocol was approved by the Institutional Animal Care and Use Committee of Yonsei University College of Medicine and Cardiovascular Research Institute, and conforms to the guidelines of the American Heart Association.

\section{Generation of Htr3a-Targeted KO Mice}

Mice were housed on a 12-h light/dark cycle in climatecontrolled, pathogen-free barrier facilities. Htr3a-targeted KO mice (B6.129X1-Htr3atmljul/J) were purchased from Jackson laboratory. Htr $3 a^{-1-}$ mice were backcrossed with C57BL/6J mice for more than 14 generations and were used for experiments when they were age of 8-12 weeks. Mating was confirmed by the presence of a vaginal plug the next morning, and was designated day 0 of gestation (G0). RNA extraction, reverse transcription polymerase chain reaction (RT-PCR), and real time RT-PCR were performed as previously described. ${ }^{15}$ The following primer sequences were used: Htr3a primers 5'-AAATCAGGGCGAGTGGGAGCTG-3' and 5'-GACACGATGATGAGGAAGACTG-3', and Tph1 primers 5'-ACCATGATTGAAGACAACAAGGAG-3' and 5'-TCAACTGTTCTCGGCTGATG-3'.

\section{Physiological Tests}

All physiological tests were performed during non-pregnant (NP) and late pregnant (LP; G16 18) stages. All procedures were performed after an anesthethic (isoflurane/ $\mathrm{O}_{2}$ ) was administered via inhalation. Body temperature was maintained at $37 \pm 0.5^{\circ} \mathrm{C}$ by using a heating pad.

Echocardiography A high-performance cardiovascular ultrasound system with a 15L8 $15 \mathrm{MHz}$ linear array transducer at a frame rate of 100 frames/s was used to perform the echocardiography. Two-dimensional views were acquired in the short-axis and parasternal long-axis view. M-mode recordings were acquired in the short-axis view at the level of the papillary muscles. The left ventricular (LV) chamber dimensions (LV internal dimension diastole, $\mathrm{LV}$ internal dimension systole, and wall thickness) were measured from the M-mode recordings. The LV fractional shortening (FS) and ejection fraction $(\mathrm{EF})$ were calculated as follows:

$\mathrm{FS}(\%)=((\mathrm{LV}$ internal dimension diastole- $\mathrm{LV}$ internal dimension systole)/LV internal dimension diastole $) \times 100$

$\mathrm{EF}(\%)=((\mathrm{LV}$ end-diastolic volume-LV end-systolic volume $) /$ LV end-diastolic volume $) \times 100$

Electrocardiography The ECG leads I, II and III were recorded using a data acquisition system (MP100 and Acknowledge software, Biopac Systems Inc). The QT interval was measured from the start of the QRS complex to the end of the $\mathrm{T}$ wave; the end of $\mathrm{T}$ wave was defined as the point of return to the isoelectric line. The corrected QT interval (QTc) was calculated by dividing the QT interval by the square root of the preceding R-R interval (Figure S1). To determine if pharmacologic activation of Htr3 could shorten the QT interval, we measured the QT intervals after an intra-peritoneal injection of serotonin $(100 \mu \mathrm{mol} / \mathrm{L})$ and a Htr3 agonist, m-CPBG $(200 \mathrm{nmol} / \mathrm{L})$.

Electrophysiological Studies Electrophysiological studies were performed in the mice as previously described. ${ }^{16,17} \mathrm{~A}$ jugular vein cutdown was performed to gain access to the right internal jugular vein. An octapolar catheter (Millar Instruments, TX, USA) was positioned in the right atrium and ventricle via the jugular vein. Programmed electrical stimulation was performed using a standard protocol with 100-ms drive trains and single extrastimuli to measure the function of the atrioventricular node and conduction properties of the atrial and ventricular tissue. The sinus node function was determined by measuring the sinus node recovery time (SNRT) following $10 \mathrm{~s}$ of pacing at 3 cycle lengths $(120,100$ and $80 \mathrm{~ms})$. Burst pacing was performed with eight $50 \mathrm{~ms}$ bursts and four $30 \mathrm{~ms}$ burst episodes for up to a total burst pacing duration of $1 \mathrm{~min}$. Programmed electrical stimulation for induction of arrhythmias was performed with single, double, and triple extrastimuli for up to a minimum coupling interval of $10 \mathrm{~ms}$, as previously described. ${ }^{16}$ After the interventional study, including ventricular pacing, the mouse hearts were harvested and weighed.

\section{Optical Mapping}

Optical mapping was performed in 6 mice from each group. After performing a median sternotomy, the hearts were rapidly excised and immersed in cold Tyrode's solution (composition in $\mathrm{mmol} / \mathrm{L}: 125 \mathrm{NaCl}, 4.5 \mathrm{KCl}, 0.25 \mathrm{MgCl}_{2}, 24 \mathrm{NaHCO}_{3}, 1.8$ $\mathrm{NaH}_{2} \mathrm{PO}_{4}, 1.8 \mathrm{CaCl}_{2}$, and 5.5 glucose). The ascending aorta was immediately cannulated and perfused with $37^{\circ} \mathrm{C}$ Tyrode's solution equilibrated with $95 \% \mathrm{O}_{2}$ and $5 \% \mathrm{CO}_{2}$ to maintain a $\mathrm{pH}$ of 7.4. For performing the optical mapping, the contractility was inhibited by $10-17 \mu \mathrm{mol} / \mathrm{L}$ of blebbistatin. ${ }^{18,19}$ Then, the hearts were stained with RH237 (Invitrogen, California, USA), and they were excited with quasi-monochromatic light $(520 \pm 30 \mathrm{~nm})$ from 2 green LED lamps. Emitted light was collected by a camera (MiCAM Ultima; BrainVision, Tokyo, Japan) with a 610 -nm long pass filter at $1 \mathrm{~ms} /$ frame and $100 \times 100$ pixels, with a spatial resolution of $0.5 \times 0.5 \mathrm{~mm}^{2} /$ pixel. The action potential duration (APD) was measured from the $(\mathrm{d} F / \mathrm{d} t)$ max to $90 \%$ (APD 90 ) and $70 \%$ recovery to baseline (APD70). The mean APD was calculated for each heart by averaging the APD from a region of the ventricle consisting of $10 \times 10$ pixels or the 100 APD from each heart. To determine if the activation of Htr3 could shorten the APD, we measured the APD 90 and APD 70 after infusion of serotonin $(100 \mu \mathrm{mol} / \mathrm{L}), \mathrm{m}-\mathrm{CPBG}(200 \mathrm{nmol} / \mathrm{L})$ and $\mathrm{Htr} 3$ antagonist, ondansertron $(1 \mu \mathrm{mol} / \mathrm{L})$, in wild mice. 
A

(a) Wild NP

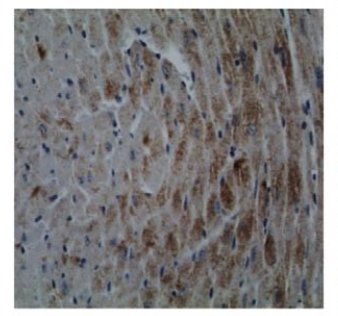

C

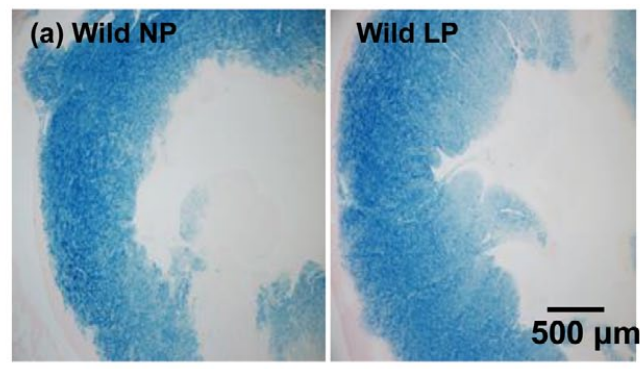

B (b) $H$ tr $3 a^{-/ / N P}$

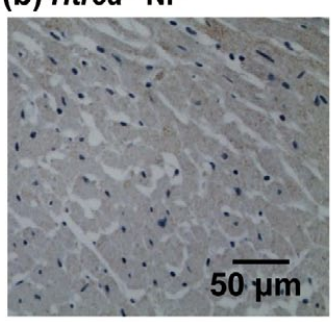

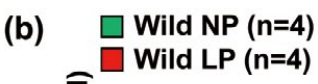

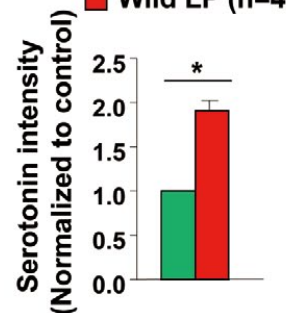

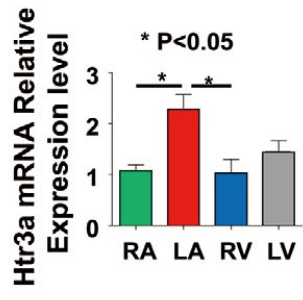

D

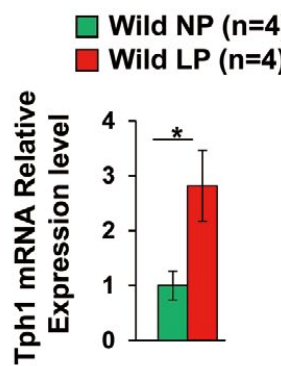

Figure 1. Presence of serotonin receptor type $3(\mathrm{Htr} 3 \mathrm{a})$ in mice hearts. (A) Immunohistochemical staining of the Htr3a in the ventricle of (a) wild-type non-pregnant (NP) and (b) $\mathrm{Htr}_{\mathrm{r}} \mathrm{a}^{-1-} \mathrm{NP}$ mice. Note the absence of Htr3a in the Htr3a-l- mouse hearts. (B) mRNA expression of Htr3a. (C) Immunohistochemical staining (a) and a comparison (b) of serotonin between wild-type NP and LP mice hearts. (D) Comparison of tryptophan hydroxylase 1 (Tph1) between wild NP and late pregnancy (LP) mice. Data are expressed as the mean \pm SEM.

\section{Histology and Immunohistochemical Staining}

For the histology, 5 hearts from each group were fixed in $4 \%$ $(\mathrm{w} / \mathrm{v})$ paraformaldehyde in phosphate buffered saline for $4 \mathrm{~h}$ at $4^{\circ} \mathrm{C}$, before being embedded in paraffin. Tissue slides were stained with Hematoxylin and Eosin. Immunohistochemical staining was performed using polyclonal anti-Htr3a antibody (Sigma Aldrich), and anti-serotonin antibody (ImmunoStar). To visualize the bound antibodies, we used a VECTASTAIN ${ }^{\circledR}$ ABC Kit (Vector labs) and a DAB Substrate Kit (Vector laboratories).

\section{Statistical Analysis}

Data were expressed as the mean \pm SEM. An analysis of variance with a post-hoc test, a Tukey's test, was used to compare the means of the continuous variables that were approximately normally distributed among the groups. The categorical variables are reported as the count (percentage) and were compared by using a Fisher's exact test. The SPSS statistical package (SSPS Inc, Chicago, IL, USA) was used to perform all statistical evaluations. A P value of $\leq 0.05$ was considered statistically significant.

\section{Results}

\section{Htr3 Expression in Mouse Hearts}

In the immunohistochemical staining, Htr3a was detected in the left ventricle of wild type mice, but not in that of $\mathrm{Htr} \mathrm{a}^{-/-}$ mice (Figure 1A). Htr3a mRNA was expressed in the wild type, but was not observed in the $\mathrm{Htr}_{3} \mathrm{a}^{--}$mouse hearts. The $\mathrm{Htr} 3 \mathrm{a}(\mathrm{n}=4)$ was higher in the left atrium (LA) than in the right atrium (RA) $(2.29 \pm 0.5$ vs. $1.08 \pm 0.22, \mathrm{P}=0.02)$ and in the right ventricle (RV) $(2.29 \pm 0.5$ vs. $1.03 \pm 0.5, \mathrm{P}=0.02)$ (Figure $1 \mathrm{~B}$ ).
Serotonin was stained in the wild-type mouse hearts at baseline and during pregnancy (Figure 1C-a). Compared with the wild NP mice, the expression level of serotonin (Figure 1C-b) and Tph1 mRNA (Figure 1D) was significantly increased in the wild LP mouse hearts.

\section{Morphological Changes}

The LP mice had an increased heart weight compared with the $\mathrm{NP}$ mice regardless of any mutations $(\mathrm{P}<0.001)$. However, the heart/body weight did not differ among the groups (Figure 2A). An echocardiography was performed on 6 mice in each group. An echocardiographic analysis also showed structurally normal hearts in the Htr3a $a^{-1}$ mice $(n=6)$. The LP mice $(n=6)$ had an increased LV end-diastolic dimension compared with the NP mice regardless of the genetic background (Figure 2B, Table S1). There was no significant difference in the LV EF among the groups (Figure 2B).

\section{Htr3-- Mice Showed a Prolonged QT Interval During Pregnancy}

Figure 3A shows the ECG lead II of the mice from each group. The heart rate, the interval between R-wave and R-wave (RR), and the interval between $\mathrm{P}$-wave and R-wave (PR) intervals did not differ between the wild-type and $\mathrm{Htr}_{3} \mathrm{a}^{-1-}$ mice during the NP and LP stages. Compared with the NP wild-type mice $(\mathrm{n}=4)$, the QT (NP: $58.0 \pm 2.8$ vs. LP: $80.5 \pm 1.0 \mathrm{~ms}, \mathrm{P}<0.001)$ and QTc intervals (NP: $171.2 \pm 16.8$ vs. LP: $247.7 \pm 14.3 \mathrm{~ms}$, $\mathrm{P}<0.001)$ were prolonged in the LP wild-type mice $(\mathrm{n}=4)$. The QT (NP: 68.8 \pm 5.4 vs. LP: $92.0 \pm 8.4 \mathrm{~ms}, \mathrm{P}<0.001$ ) and QTc intervals (NP: $187.9 \pm 18.7$ vs. LP: $275.6 \pm 11.0 \mathrm{~ms}, \mathrm{P}<0.001)$ were longer in the LP Htr3a $a^{-1-}$ mice $(n=6)$ than in the NP 
A
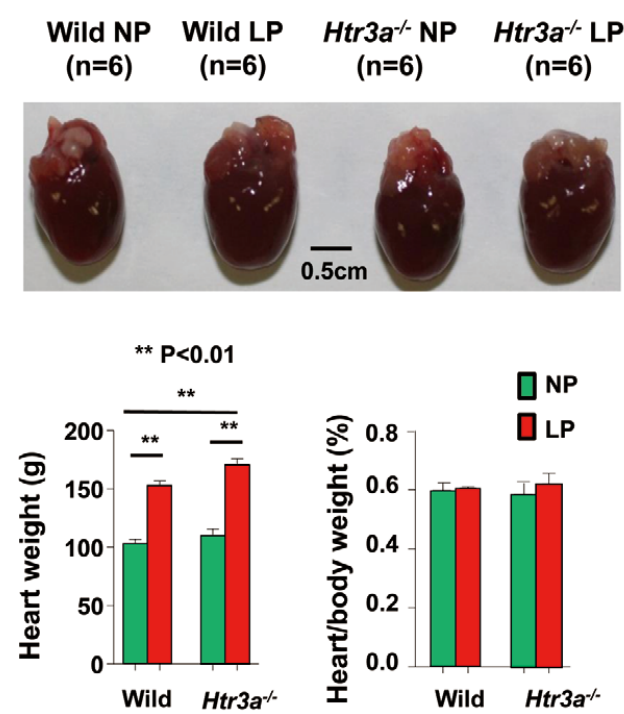

B
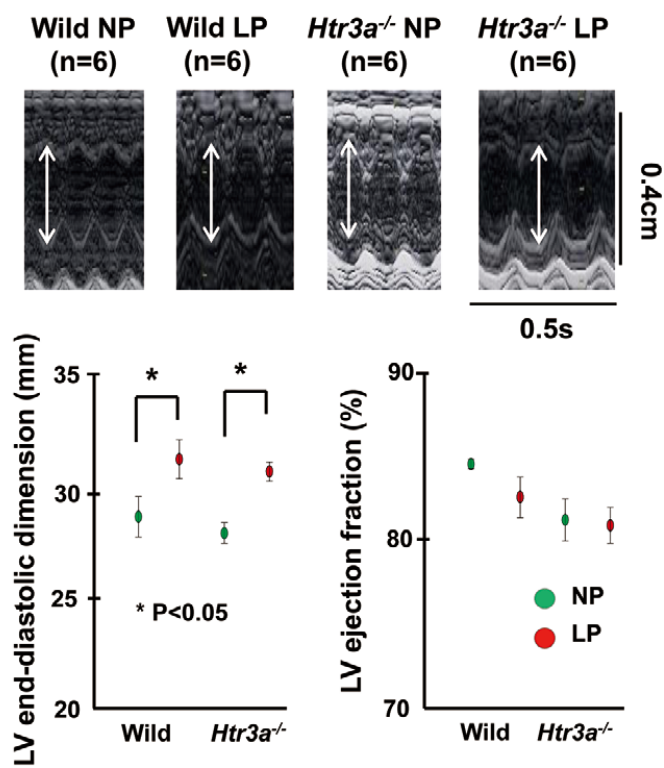

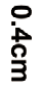

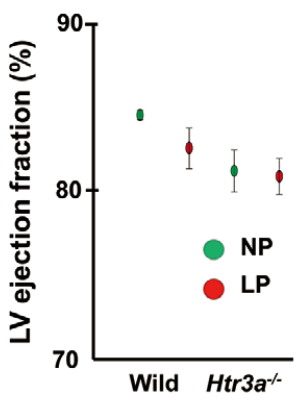

Figure 2. Morphological changes in the hearts after pregnancy. (A) Gross view of mouse hearts (Upper panels). Heart weight and heart/body weight ratio (Lower panels). Data are expressed as the mean \pm SEM. (B) Echocardiographic measurements. Upper panels: typical examples of echocardiography; Lower panels: the comparison of the left ventricular (LV) ejection fraction and end-diastolic dimension.

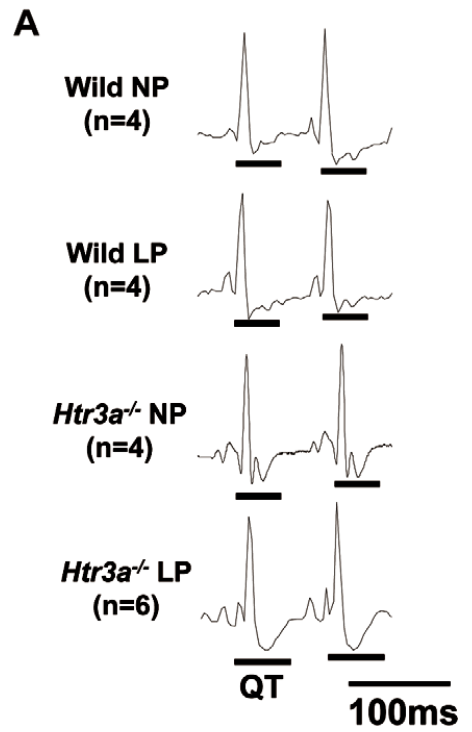

B
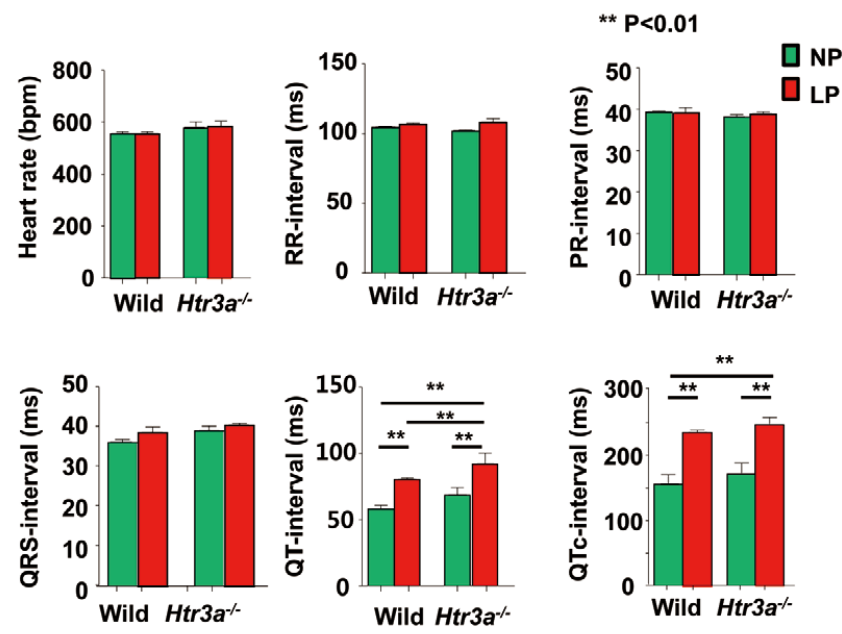

Figure 3. Measurement of the QT intervals. (A) Typical examples of ECG lead I. (B) Heart rate, RR, PR, PQ, QRS, QT, and QTc intervals. Data are expressed as the mean \pm SEM.

$H$ tr3a $a^{-1-}$ mice $(\mathrm{n}=4)$ (Figure 3B).

\section{Spontaneous VT and Sudden Death in Htr3a-- Mice During Pregnancy}

Figure 4A shows the example of spontaneous ventricular tachycardia (VT, asterisks in Middle panel) and ventricular fibril- lation (VF, Lower panel) in the Htr3a-- mice during pregnancy.

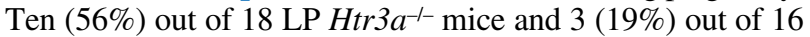
NP $\mathrm{Htr}_{3} \mathrm{a}^{-1}$ mice had spontaneous VT. However, VT was not observed in the wild-type NP $(\mathrm{n}=12)$ and LP mice $(\mathrm{n}=12)$. The

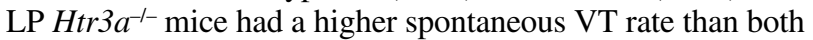
the $\mathrm{NP}(\mathrm{P}=0.002)$ and $\mathrm{LP}$ wild-type mice $(\mathrm{P}=0.002)$ (Figure $4 \mathrm{~B})$. 
A

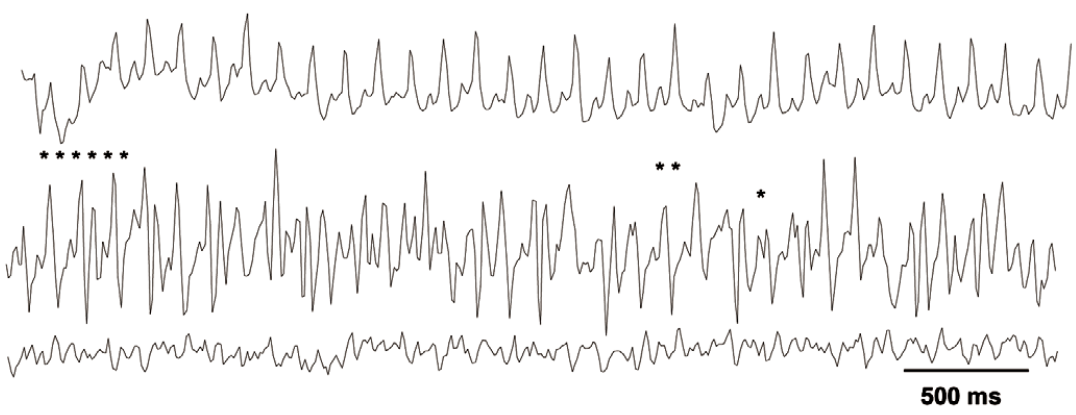

B

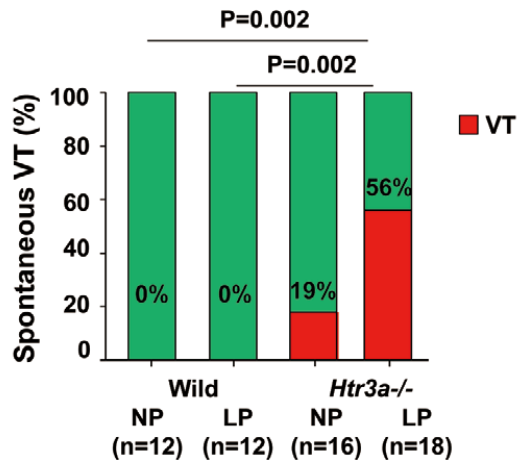

C

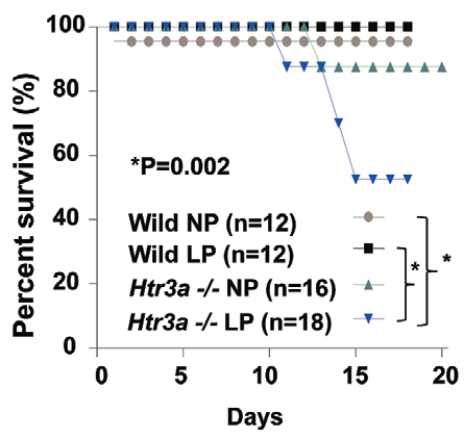

Figure 4. Spontaneous ventricular tachycardia (VT) and increased mortality in Htr3a-l- late pregnancy (LP) mice. (A) ECG findings showing VT (Middle panel) and ventricular fibrillation (VF; Lower panel). (B) Spontaneous VT/NF ratio in each group. (C) KaplanMeier survival curve for each group.

\begin{tabular}{|c|c|c|c|c|}
\hline Parameter & $\begin{array}{c}\text { Wild NP } \\
(n=3)\end{array}$ & $\begin{array}{c}\text { Wild LP } \\
(n=3)\end{array}$ & $\begin{array}{c}H \text { tr3a-l- NP } \\
\quad(n=6)\end{array}$ & $\begin{array}{c}H \text { tr3a-l- LP } \\
(\mathrm{n}=3)^{\star}\end{array}$ \\
\hline SNRT, ms & $147.0 \pm 14.2$ & $114 \pm 12.3$ & $186.7 \pm 32.1$ & $314.7 \pm 0.0^{\dagger}$ \\
\hline cSNRT, ms & $168.0 \pm 4.0$ & $127.0 \pm 24.0$ & $296.7 \pm 36.2^{\dagger}$ & $353.7 \pm 32.7^{\dagger}$ \\
\hline AVBCL, ms & $22.7 \pm 4.6$ & $28.7 \pm 12.1$ & $34.7 \pm 14.2$ & - \\
\hline \multicolumn{5}{|l|}{ AVNERP, ms } \\
\hline $\mathrm{S}_{1}=100 \mathrm{~ms}$ & $16.3 \pm 0.6$ & $16.3 \pm 0.6$ & $16.3 \pm 1.0$ & - \\
\hline $\mathrm{S}_{1}=90 \mathrm{~ms}$ & $16.0 \pm 0.0$ & $16.0 \pm 0.0$ & $16.0 \pm 0.0$ & - \\
\hline $\mathrm{S}_{1}=80 \mathrm{~ms}$ & $16.0 \pm 0.0$ & $16.0 \pm 0.0$ & $15.5 \pm 0.8$ & - \\
\hline VABCL, ms & $22.3 \pm 1.5$ & $31.3 \pm 10.3$ & $31.0 \pm 17.0$ & - \\
\hline \multicolumn{5}{|l|}{ VERP, ms } \\
\hline $\mathrm{S}_{1}=100 \mathrm{~ms}$ & $16.3 \pm 0.6$ & $16.0 \pm 0.0$ & $15.0 \pm 6.3$ & - \\
\hline $\mathrm{S}_{1}=90 \mathrm{~ms}$ & $16.0 \pm 0$ & $15.3 \pm 0.6$ & $15.8 \pm 6.5$ & - \\
\hline $\mathrm{S}_{1}=80 \mathrm{~ms}$ & $16.0 \pm 0$ & $15.3 \pm 0.6$ & $16.2 \pm 6.6$ & - \\
\hline
\end{tabular}

AVBCL, atrioventricular block cycle length; AVNERP, atrioventricular node effective refractory period; (c)SNRT, (corrected) sinus node recovery time; LP, late pregnancy; NP, non-pregancy; VABCL, ventriculoatrial block cycle length; VERP, ventricular effective refractory period. *Several parameters could not be measured in the Htr3a- $\mathrm{a}^{-I} \mathrm{LP}$ group because of the induction of ventricular fibrillation. †Significant difference from the control: $P$-value $<0.05$. The AVNERP and VERP were measured using a $S_{1}$ pacing $C L$ of $100 \mathrm{~ms}$. The SNRT was measured after $110 \mathrm{~ms}$ pacing.

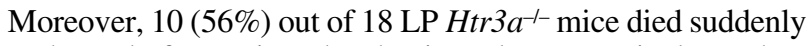
at the end of gestation, thus having a lower survival rate than the $\mathrm{NP}(\mathrm{P}=0.002)$ and LP wild-type mice $(\mathrm{P}=0.002$, Figure $4 \mathrm{C})$.

\section{Electrophysiological Characteristics}

The electrophysiological characteristics are presented in Table. Compared with the control $(\mathrm{n}=4)$, the SNRT $(147.0 \pm 14.2$ vs. $314.7 \pm 14.6 \mathrm{~ms}, \mathrm{P}=0.001)$ and corrected sinus node recov- ery time (cSNRT) $(168.0 \pm 4.0$ vs. $353.7 \pm 32.7 \mathrm{~ms}, \mathrm{P}=0.001)$ were significantly longer in the Htr $3 a^{-1}$ LP mice $(\mathrm{n}=4)$. Because of VT or VF induction, the exact values of the atrioventricular block cycle length (AVBCL), atrioventricular node effective refractory period (AVNERP), ventriculoatrial block cycle length (VABCL), ventricular effective refractory period (VERP) could not be measured in the Htr3a $a^{-1-}$ LP mice (Table). 


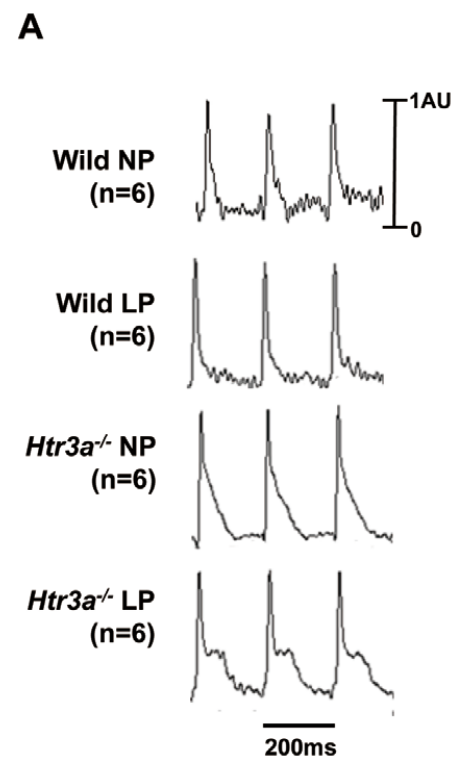

B

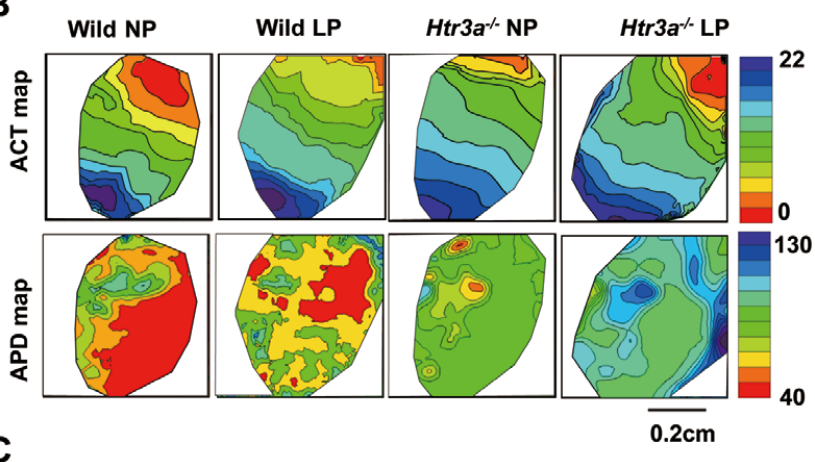

C

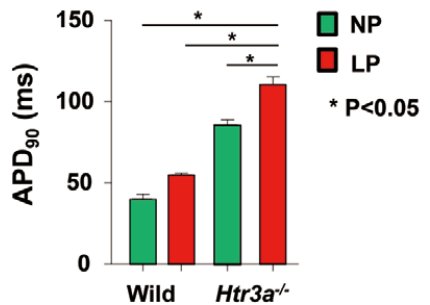

Figure 5. Optical mapping in each group. (A) Typical examples of action potential tracings. (B) Activation (Upper panels) and action potential duration (APD) maps (Lower panels) in each group. (C) Comparison of the APD9o.

A

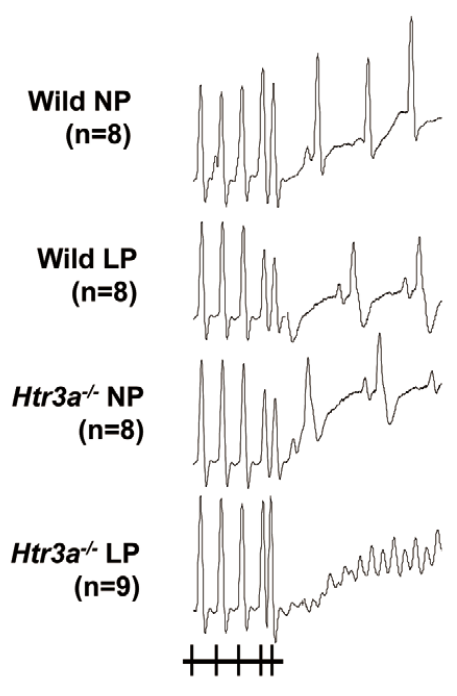

S1-S2: $80-40 \mathrm{~ms}$
B

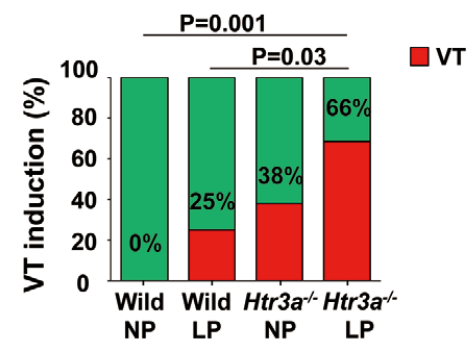

C
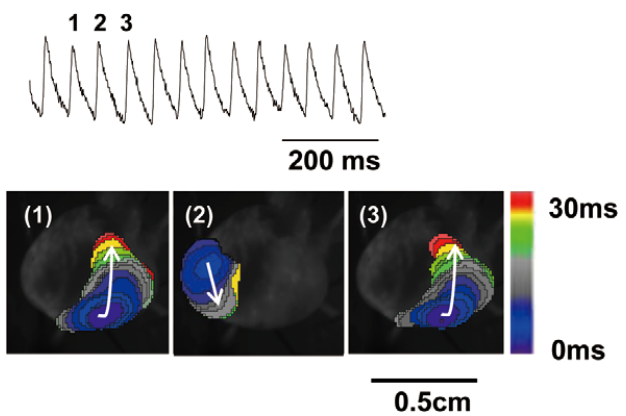

Figure 6. Ventricular tachycardia (VT) inducibility test. (A) VT induction test. Note the induction of VT in the late pregnancy (LP) $\mathrm{Htr} \mathrm{a}^{-1-}$ mice with an $\mathrm{S}_{1} \mathrm{~S}_{2}$ stimulation of 80-40 ms. (B) Comparison of the VT inducibility among the groups. (C) Optical mapping of VT tracing (Upper panel) and activation maps (Lower panels).

\section{Optical Mapping Findings}

Figure 5A shows the action potential traces at the base of the LV during pacing cycle lengths of $200 \mathrm{~ms}$ in Langendorff-perfused mouse hearts. The APD was prolonged during preg- nancy in the wild-type mice and $H$ tr $3 a^{-1-}$ mice. The Htr3a deletion induced prolongation of the APD in both the NP and LP status. Figure 5B shows the activation map. The total ventricular activation time was significantly more increased in 
A

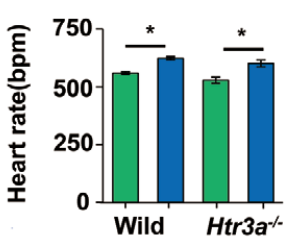

B

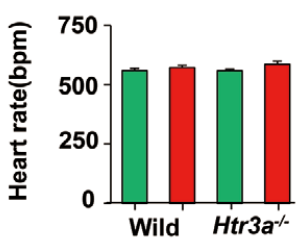

C

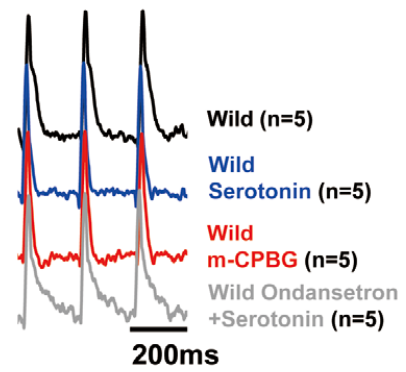

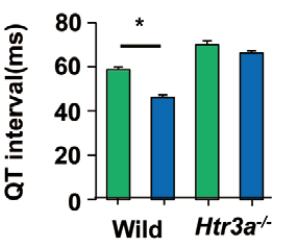
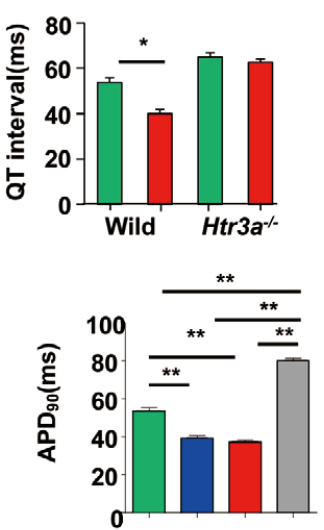
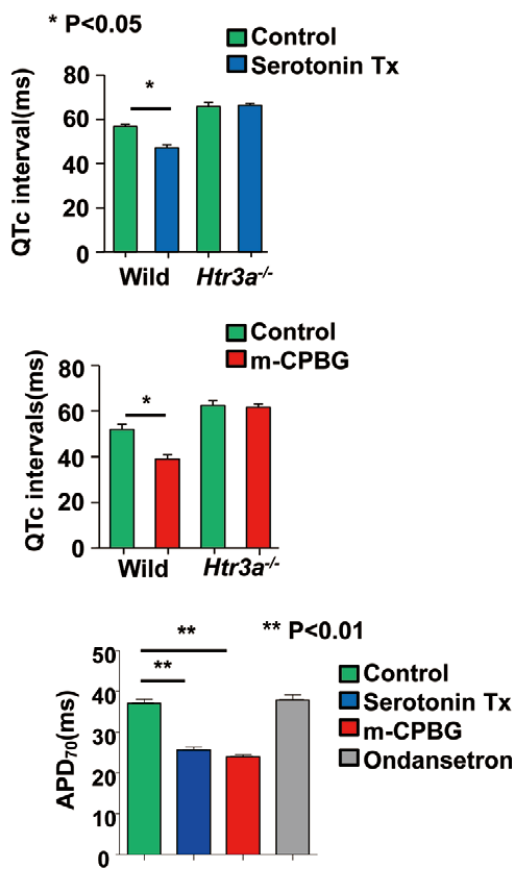

Figure 7. Effect of serotonin on QT intervals and action potential duration (APD). (A) Effects of serotonin and a serotonin receptor type 3 (Htr3) agonist, m-CPBG, on the heart rate (HR) and QT interval. Note the decreased QT intervals with serotonin and the Htr3 agonist, m-CPBG, in wild-type mice, but not in Htr3a-1- mice (B). (C) Typical examples of action potential tracings. Comparison of the APD9o and APD70. Note the shortened APD with serotonin and the Htr3 agonist, m-CPBG, in wild-type mice, but not in mice treated with the Htr3 antagonist, ondansetron. Data are expressed as the mean \pm SEM.

the LP Htr3a ${ }^{-/-}$hearts $(29.0 \pm 2.2 \mathrm{~ms})$ than in the NP wild-type hearts $(11.0 \pm 1.0 \mathrm{~ms}, \mathrm{P}<0.001)$. The APD90 of the LP Htr3a $a^{-/-}$ hearts $(114.1 \pm 7.9 \mathrm{~ms})$ was longer than that of the NP wild-type hearts $(76.6 \pm 2.1 \mathrm{~ms}, \mathrm{P}<0.001)$, LP wild-type hearts $(77.0 \pm 5.3 \mathrm{~ms}$, $\mathrm{P}<0.001)$, and NP Htr3a $a^{-1-}$ hearts $(80.5 \pm 3.2 \mathrm{~ms}, \mathrm{P}<0.001$; Figure 5C).

\section{Increased VT Vulnerability in Htr3a-/- Mice During Pregnancy}

The typical examples of induced VF are presented in Figure 6A. Figure 6B shows the comparison of the VT inducibility test among the 4 groups. VT was induced in none of the NP wildtype mice $(\mathrm{n}=8)$, in $2(25 \%)$ of the LP wild-type mice $(\mathrm{n}=8)$, in $3(38 \%)$ of the NP Htr3a $a^{-1}$ mice $(\mathrm{n}=8)$, and in $6(66 \%)$ of the LP Htr $3 a^{-1-}$ mice ( $\left.\mathrm{n}=9\right)$. The LP Htr $3 a^{-1-}$ mice had a higher VT inducibility than the NP wild-type mice $(\mathrm{P}=0.001)$ and LP wild-type mice $(\mathrm{P}=0.002)$. Figure $6 \mathrm{C}$ shows an example of a VT rotating around the LV in a counterclock wise manner.

\section{Activation of the Htr3 Shortens the QT Interval and APD}

In order to determine if the activation of the Htr3 could shorten the QT interval, we examined the effects of serotonin and an Htr3 agonist on the QT interval. An intra-peritoneal injection of serotonin $(100 \mu \mathrm{mol} / \mathrm{L})$ shortened the QTc interval in the wild-type mice (QTc, from $58.7 \pm 2.1$ to $46.3 \pm 2.1 \mathrm{~ms}$, $\mathrm{P}=0.001)$. However, serotonin failed to shorten the QTc interval in the $\mathrm{Htr} \mathrm{a}^{-/-}$mice (QTc, from $65.7 \pm 3.7$ to $66.3 \pm 1.8 \mathrm{~ms}$, $\mathrm{P}=0.81$ ) (Figure 7A). The Htr3 agonist, $\mathrm{m}-\mathrm{CPBG}$, also short- ened the QT interval in the wild-type mice (QTc, 51.9 \pm 2.3 to $39.1 \pm 1.8 \mathrm{~ms}, \mathrm{P}=0.009$ ), but not in the $\mathrm{Htr} \mathrm{a}^{-1-}$ mice (QTc, $62.5 \pm 2.2$ vs. $61.7 \pm 1.5 \mathrm{~ms}, \mathrm{P}=0.70$; Figure $7 \mathrm{~B})$. Interestingly, in both the wild-type and $\mathrm{Htr}_{3} \mathrm{a}^{-1-}$ mice, the heart rate was increased by serotonin, but not by the Htr3 agonist (m-CPBG). This finding suggested that an increase in the heart rate induced by 5 -HT was independent of Htr3.

We then examined whether the Htr3 agonist actually reduced the QT interval during a prolonged QT status. To prolong the QT interval, we used erythromycin, which is known to induce QT prolongation in mice. ${ }^{20}$ The Htr3 agonist, m-CPBG $(200 \mathrm{nmol} / \mathrm{L})$, reduced the prolonged QT interval induced by erythromycin $(200 \mu \mathrm{mol} / \mathrm{L})(\mathrm{QTc}$ from $51.9 \pm 2.0$ to $43.2 \pm 2.1 \mathrm{~ms}$, $\mathrm{P}=0.04$; Figure $\mathrm{S} 2$ ).

Finally, we evaluated the effect of Htr3 activation on APD using optical mapping. The serotonin $(100 \mu \mathrm{mol} / \mathrm{L})$ and Htr3 agonist, m-CPBG $(200 \mathrm{nmol} / \mathrm{L})$, shortened both APD90 and APD70. However, the APD shortening effect of serotonin was abolished in mice treated with the Htr3 antagonist, ondansertron $(1 \mu \mathrm{mol} / \mathrm{L})$ (Figures 7C,D).

\section{Discussion}

\section{Main Findings}

The main finding of this study was that Htr3 was present in mouse hearts. Serotonin and Tph1 in the heart are increased during pregnancy. Second, although the deletion of Htr3a did not cause any electrophysiological changes in the non-pregnant 
state, pregnant $\mathrm{Htr} 3 \mathrm{a}^{-1-}$ mice had sudden death and spontaneous VT with electrophysiological changes of the QT, APD prolongation, and an increased VT inducibility. Third, the pharmacological administration of serotonin and the Htr3 agonist shortened the QT intervals in the wild-type mice, but not in the $\mathrm{Htr}_{\mathrm{H} \mathrm{a}^{-1}}$ mice. Our results suggest that Htr3 has a role in preventing QT prolongation, especially in mouse hearts during pregnancy.

\section{Serotonin and the Heart}

Serotonin is a biogenic amine that mediates neuronal transmission both in the central and peripheral nervous systems. Outside of neurons, serotonin is present mostly in platelets and can be transferred to all organs. Many studies have reported on the relationship between serotonin and the heart function. $T p h 1^{-1-}$ mice exhibited a larger variability in the cardiac output, stroke volume, and end systolic pressure-volume relationship as compared with the control mice. ${ }^{4} \mathrm{Htr} 2 \mathrm{~b}$ is associated with valvular heart disease and heart embryogenesis. ${ }^{21,22}$ With respect to heart arrhythmias, under acute coronary ligation conditions, ventricular ectopic beats and VT/VF are increased by serotonin injection in rats. ${ }^{23} \mathrm{Htr} 4$ mediates atrial tachycardia, ${ }^{24}$ and a Htr4 blockade has a beneficial effect on atrial fibrillation. ${ }^{25}$ Recently, it was reported that mouse cardiac tissue contained mRNA for various 5-HT receptor types, including $\mathrm{Htr} 3 .^{26}$ However, the role of Htr3, a serotonin-gated nonselective cation channel, has not been demonstrated in the heart. ${ }^{27}$ In this study, we also confirmed the presence of Htr3a in mouse hearts. Moreover, we demonstrated that serotonin and Htr3 in mouse hearts were increased during pregnancy.

\section{Influence of Htr3 on the QT Interval and APD}

In this study, serotonin and the Htr3 agonist, m-CPBG, shortened the QT intervals in the wild-type but not in the $\mathrm{Htr} 3 \mathrm{a}^{-/}$ mice. Moreover, Htr3 activation shortened the APD in the wild-type but not in the mice treated with the Htr3 antagonist, ondansertron. The serotonin and Tph1 levels of the mice hearts was increased during pregnancy. The QT prolongation was more prominent in the LP Htr3a $a^{-1-}$ mice than in the LP wildtype mice. These results strongly support the role of serotonin in preventing QT prolongation through Htr3. Consistently, the QT and APD shortening effect of serotonin was abolished after the Htr3 deletion.

The maternal heart significantly adapts to the circulatory needs of pregnancy, but the effect of pregnancy on ventricular repolarization is poorly understood. Pregnancy induces electrocardiogram disturbances such as longer QT-interval prolongation. Eghbali et al $^{28,29}$ reported that fast transient outward potassium current ( $\left.I_{\mathrm{to}, \mathrm{f}}\right)$ and slow delayed rectifier potassium current (Ikslow) are downregulated in pregnancy. Especially, cardiac $\mathrm{Kv} 4.3$ channel gene expression was downregulated by approximately 3- to 5-fold, and was paralleled by a reduction in the transient outward $\mathrm{K}^{+}$currents, a longer action potential, and by prolongation of the QT interval. Because the role of $I \mathrm{Ks}$ in repolarization is smaller than that of $I_{\mathrm{to}, \mathrm{f}}$ in mice,,$^{30}$ the mechanism of the QT shortening by serotonin might be related to the increase in the Itof channel. Consistently, the QT shortening effect of serotonin and the Htr3 agonist was not observed in the $H \mathrm{tr} \mathrm{3}^{-1-}$ mice. The second possible answer might be the

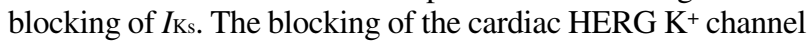
was suggested as the possible underlying mechanism for the prolongation of the cardiac repolarization. ${ }^{31}$ However, because the role of $I_{\mathrm{Ks}}$ in repolarization is small in mice, ${ }^{30}$ the possibility of $I_{\mathrm{ks}}$ involvement is relatively low. The third possible answer might be the direct involvement of non-selective cat- ion channels, such as Htr3. Recently, non-selective cation channels were reported to regulate the resting membrane potential. ${ }^{32,33} \mathrm{Htr} 3$, a serotonin-gated non-selective cation channel, can contribute to the formation of the resting membrane potential.

\section{Influence of Htr3 on SNRT}

In this study, the prolongation of the SNRT and cSNRT was observed in the $\mathrm{Hrr}^{3^{--}}$LP mice. The prolongation of the SNRT was related with sinus bradycardia. However, in this study, we could not find a difference in the heart rate between the 4 groups. This discrepancy might be explained by the fact that, in general, pregnancy is associated with a faster heart rate, which is a risk factor for arrhythmias. El Khoury et al reported that an increase in the If current density contributes to the acceleration of sinoatrial node automaticity and explains, in part, the higher heart rate observed in pregnancy. ${ }^{34}$ Another possible explanation might be the low diagnostic efficacy of SNRT. ${ }^{35,36}$ Finally, the mechanism of overdrive suppression is related to the rebound increase in the parasympathetic tone after overdrive stimulation. ${ }^{37}$

\section{Clinical Implication}

The role of serotonin in the heart has not been completely determined. Htr3 antagonists, which are widely used as antiemetics, have been reported to prolong the QT intervals and to be related to tosades de pointes in high concentrations.9-12 This finding suggests that serotonin and Htr3 might be related to cardiac repolarization. Recently, it was reported that mouse cardiac tissue contained mRNA for Htr $3 .{ }^{26}$ Consistently, this study demonstrated that the pharmalogical administration of serotonin and a Htr3 agonist decreased the QT interval in the wild type, but not in the Htr $3^{-1-}$ mice. Pregnancy naturally induces physiologic hypertrophy and QT prolongation. We found the level of serotonin and a rate-limiting enzyme of serotonin, Tph1, were increased in the mouse heart during pregnancy. No wild-type mice had cardiovascular events during pregnancy. However, surprisingly, the $\mathrm{Htr}^{-1-}$ mice had a marked fatal arrhythmia and sudden death during pregnancy. Conclusively, this study suggests that serotonin has a role in shortening the repolarization period via Htr3, and this role is extremely important during pregnancy.

\section{Study Limitations}

This study demonstrated that serotonin and Tph1 were increased during pregnancy. Peripherally, serotonin is stored in platelets; however, we could not exactly present the source of the serotonin that affects the heart. Pregnancy induces electrocardiogram disturbances such as longer QT-interval prolongation, which is related to the reduction in the Ito current and Kv4.3 channel gene downregulation. By using $\mathrm{Htr}^{-1-}$ LP mice, we demonstrated that serotonin has an important role via Htr3 in preventing further prolongation of the QT interval during pregnancy. However, the evaluation of major repolarizing outward potassium current in mouse such as Itof using the patch-clamp method is important to reveal the exact mechanism. Finally, because all 10 mice with spontaneous ventricular tachycardia died suddenly, those mice might have died of ventricular arrhythmias. However, we could not provide the exact cause of death in those mice because we did not record telemetry monitoring in all mice before death.

\section{Conclusions}

Htr3a is present in mouse hearts. Serotonin and Tph1 were 
increased during pregnancy. The deletion of Htr3a was related to fatal arrhythmias and sudden cardiac death during pregnancy, and its activation reversed the QT prolongation.

\section{Acknowledgments}

Funding Sources: This study was supported, in part, by research grants from the Korean Heart Rhythm Society (2011-3), the Basic Science Research Program through the National Research Foundation of Korea funded by the Ministry of Education, Science and Technology (NRF2010-0021993, NRF-2012R1A2A2A02045367, B.J.; NRF-2011-0023387, NRF-2012M3A9B2027974, H.K.), and a grant from the Korean Healthcare technology R\&D project funded by the Ministry of Health \& Welfare (HI12C1552, B.J.; HI11C1964, H.K.).

\section{References}

1. Saxena PR, Villalon CM. 5-Hydroxytryptamine: A chameleon in the heart. Trends Pharmacol Sci 1991; 12: 223-227.

2. Wade PR, Chen J, Jaffe B, Kassem IS, Blakely RD, Gershon MD. Localization and function of a 5-HT transporter in crypt epithelia of the gastrointestinal tract. $J$ Neurosci 1996; 16: 2352-2364.

3. Nebigil CG, Choi DS, Dierich A, Hickel P, Le Meur M, Messaddeq $\mathrm{N}$, et al. Serotonin 2B receptor is required for heart development. Proc Natl Acad Sci USA 2000; 97: 9508-9513.

4. Côté F, Thévenot E, Fligny C, Fromes Y, Darmon M, Ripoche MA, et al. Disruption of the nonneuronal tph1 gene demonstrates the importance of peripheral serotonin in cardiac function. Proc Natl Acad Sci USA 2003; 100: $13525-13530$.

5. Hoyer D, Clarke DE, Fozard JR, Hartig PR, Martin GR, Mylecharane EJ, et al. International Union of Pharmacology classification of receptors for 5-hydroxytryptamine (Serotonin). Pharmacol Rev 1994; 46: 157-203.

6. Maricq AV, Peterson AS, Brake AJ, Myers RM, Julius D. Primary structure and functional expression of the $5 \mathrm{HT} 3$ receptor, a serotoningated ion channel. Science 1991; 254: 432-437.

7. Derkach V, Surprenant A, North RA. 5-HT3 receptors are membrane ion channels. Nature 1989; 339: 706-709.

8. Davies PA, Pistis M, Hanna MC, Peters JA, Lambert JJ, Hales TG, et al. The 5-HT3B subunit is a major determinant of serotonin-receptor function. Nature 1999; 397: 359-363.

9. Benedict CR, Arbogast R, Martin L, Patton L, Morrill B, Hahne W. Single-blind study of the effects of intravenous dolasetron mesylate versus ondansetron on electrocardiographic parameters in normal volunteers. J Cardiovasc Pharmacol 1996; 28: $53-59$.

10. Jantunen IT, Kataja VV, Muhonen TT, Parviainen T. Effects of granisetron with doxorubicin or epirubicin on ECG intervals. Cancer Chemother Pharmacol 1996; 37: 502-504.

11. Boike SC, Ilson B, Zariffa N, Jorkasky DK. Cardiovascular effects of i.v. granisetron at two administration rates and of ondansetron in healthy adults. Am J Health Syst Pharm 1997; 54: 1172-1176.

12. Havrilla PL, Kane-Gill SL, Verrico MM, Seybert AL, Reis SE. Coronary vasospasm and atrial fibrillation associated with ondansetron therapy. Ann Pharmacother 2009; 43: 532-536.

13. Satoh H, Sano M, Suwa K, Saotome M, Urushida T, Katoh H, et al. Pregnancy-related acute myocardial infarction in Japan: A review of epidemiology, etiology and treatment from case reports. Circ J 2013; 77: 725-733.

14. Tanaka H, Kamiya C, Katsuragi S, Tanaka K, Miyoshi T, Tsuritani $\mathrm{M}$, et al. Cardiovascular events in pregnancy with hypertrophic cardiomyopathy. Circ J 2014; 78: 2501-2506.

15. Kim H, Toyofuku Y, Lynn FC, Chak E, Uchida T, Mizukami H, et al. Serotonin regulates pancreatic beta cell mass during pregnancy. Nat Med 2010; 16: 804-808.

16. Li N, Timofeyev V, Tuteja D, Xu D, Lu L, Zhang Q, et al. Ablation of a Ca2+-activated $\mathrm{K}+$ channel (SK2 channel) results in action potential prolongation in atrial myocytes and atrial fibrillation. $J$ Physiol 2009; 587: 1087-1100

17. Berul CI, Aronovitz MJ, Wang PJ, Mendelsohn ME. In vivo cardiac electrophysiology studies in the mouse. Circulation 1996; 94: 2641 2648.

18. Joung B, Tang L, Maruyama M, Han S, Chen Z, Stucky M, et al. Intracellular calcium dynamics and acceleration of sinus rhythm by beta-adrenergic stimulation. Circulation 2009; 119: 788-796.

19. Park H, Park H, Lee D, Oh S, Lim J, Hwang HJ, et al. Increased phosphorylation of $\mathrm{Ca}(2+)$ handling proteins as a proarrhythmic mechanism in myocarditis. Circ J 2014; 78: 2292-2301.
20. Guo J, Zhan S, Lees-Miller JP, Teng G, Duff HJ. Exaggerated block of hERG $(\mathrm{KCNH} 2)$ and prolongation of action potential duration by erythromycin at temperatures between 37 degrees $\mathrm{C}$ and 42 degrees C. Heart Rhythm 2005; 2: 860-866.

21. Rothman RB, Baumann MH, Savage JE, Rauser L, McBride A, Hufeisen SJ, et al. Evidence for possible involvement of 5-HT2B receptors in the cardiac valvulopathy associated with fenfluramine and other serotonergic medications. Circulation 2000; 102: 2836-2841.

22. Nebigil CG, Hickel P, Messaddeq N, Vonesch JL, Douchet MP, Monassier L, et al. Ablation of serotonin 5-HT2B receptors in mice leads to abnormal cardiac structure and function. Circulation 2001; 103: $2973-2979$.

23. El-Mahdy S. 5-Hydroxytryptamine (serotonin) enhances ventricular arrhythmias induced by acute coronary artery ligation in rats. Res Commun Chem Pathol Pharmacol 1990; 68: 383-386.

24. Medhurst AD, Kaumann AJ. Characterization of the 5-HT4 receptor mediating tachycardia in piglet isolated right atrium. Br J Pharmacol 1993; 110: $1023-1030$.

25. Leftheriotis DI, Theodorakis GN, Poulis D, Flevari PG, Livanis EG, Iliodromitis EK, et al. The effects of 5-HT4 receptor blockade and stimulation, during six hours of atrial fibrillation. Europace 2005; 7: $560-568$.

26. Mekontso-Dessap A, Brouri F, Pascal O, Lechat P, Hanoun N, Lanfumey L, et al. Deficiency of the 5-hydroxytryptamine transporter gene leads to cardiac fibrosis and valvulopathy in mice. Circulation 2006; 113: 81-89.

27. Kaumann AJ, Levy FO. 5-hydroxytryptamine receptors in the human cardiovascular system. Pharmacol Ther 2006; 111: 674-706.

28. Eghbali M, Deva R, Alioua A, Minosyan TY, Ruan H, Wang Y, et al. Molecular and functional signature of heart hypertrophy during pregnancy. Circ Res 2005; 96: 1208-1216.

29. Eghbali M, Wang Y, Toro L, Stefani E. Heart hypertrophy during pregnancy: A better functioning heart? Trends Cardiovasc Med 2006; 16: $285-291$.

30. Nerbonne JM, Nichols CG, Schwarz TL, Escande D. Genetic manipulation of cardiac $\mathrm{K}(+)$ channel function in mice: What have we learned, and where do we go from here? Circ Res 2001; 89: 944956.

31. Kuryshev YA, Brown AM, Wang L, Benedict CR, Rampe D. Interactions of the 5-hydroxytryptamine 3 antagonist class of antiemetic drugs with human cardiac ion channels. J Pharmacol Exp Ther 2000; 295: $614-620$.

32. Lu B, Su Y, Das S, Liu J, Xia J, Ren D. The neuronal channel NALCN contributes resting sodium permeability and is required for normal respiratory rhythm. Cell 2007; 129: $371-383$.

33. Kruse M, Schulze-Bahr E, Corfield V, Beckmann A, Stallmeyer B, Kurtbay G, et al. Impaired endocytosis of the ion channel TRPM4 is associated with human progressive familial heart block type I. J Clin Invest 2009; 119: 2737-2744.

34. El Khoury N, Mathieu S, Marger L, Ross J, El Gebeily G, Ethier N, et al. Upregulation of the hyperpolarization-activated current increases pacemaker activity of the sinoatrial node and heart rate during pregnancy in mice. Circulation 2013; 127: 2009-2020.

35. Joung B, Hwang HJ, Pak HN, Lee MH, Shen C, Lin SF, et al. Abnormal response of superior sinoatrial node to sympathetic stimulation is a characteristic finding in patients with atrial fibrillation and symptomatic bradycardia. Circ Arrhythm Electrophysiol 2011; 4: 799807.

36. Mun HS, Shen C, Pak HN, Lee MH, Lin SF, Chen PS, et al. Chronic amiodarone therapy impairs the function of the superior sinoatrial node in patients with atrial fibrillation. Circ J 2013; 77: 2255-2263.

37. Joung B, Shinohara T, Zhang H, Kim D, Choi EK, On YK, et al. Tachybradycardia in the isolated canine right atrium induced by chronic sympathetic stimulation and pacemaker current inhibition. Am J Physiol Heart Circ Physiol 2010; 299: H634-H642.

\section{Supplementary Files}

\section{Supplementary File 1}

Figure S1. Corrected QT interval is calculated by dividing the QT interval by the square root of the preceding $\mathrm{R}-\mathrm{R}$ interval.

Figure S2. Serotonin receptor type 3 (Htr3) agonist actually reduced the QT interval in a prolonged QT status.

Table S1. Echocardiographic measurements

Please find supplementary file(s);

http://dx.doi.org/10.1253/circj.CJ-14-1074 